


\title{
CLOUD KISSER
}

\author{
$\left(\mathrm{R}_{\mathrm{AG}}\right)$
}

RAYMOND BIRCH

Comp. of (Poweder Rus!
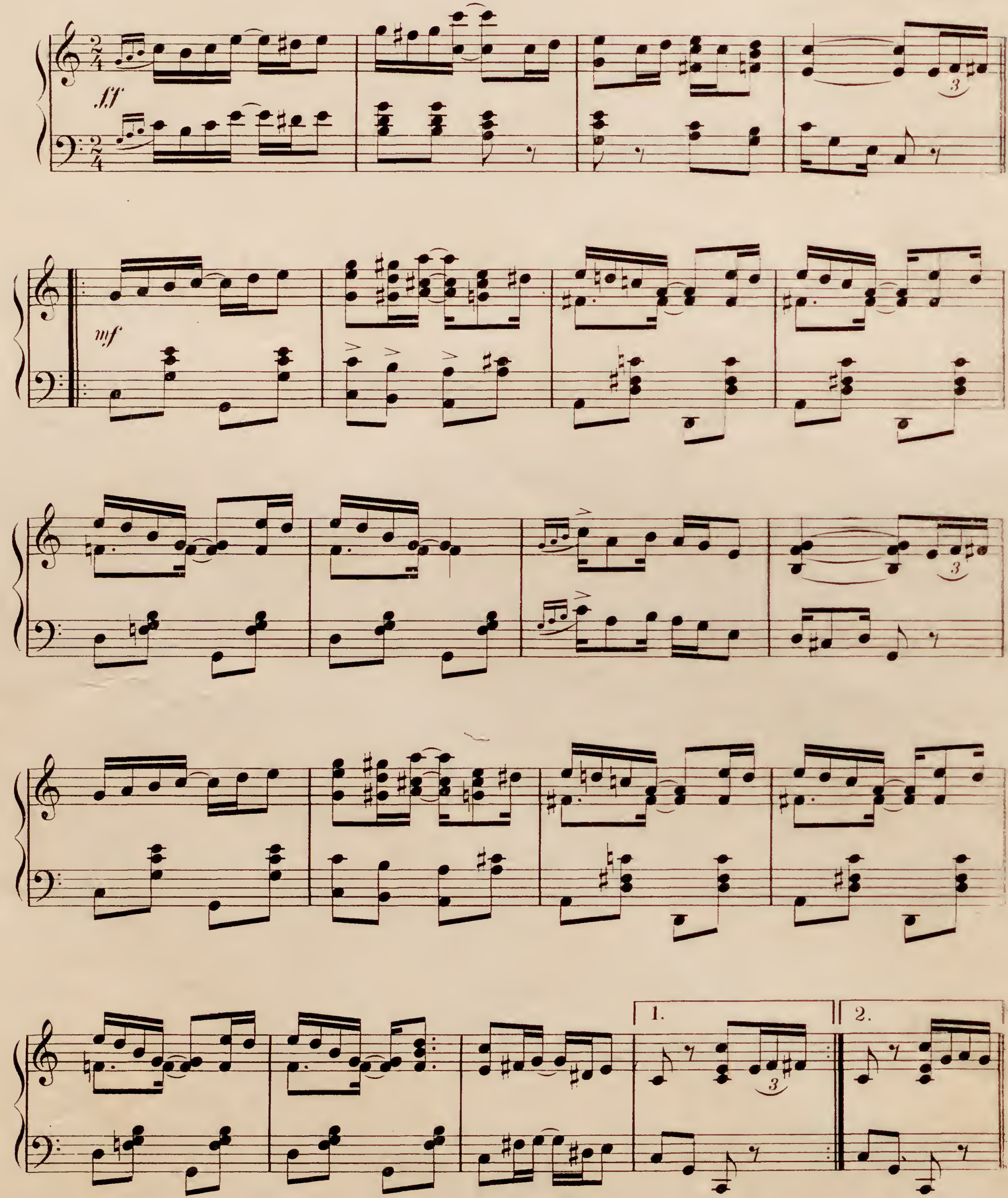

Copyright MCMXI by Johnson Pub. Co., Kansas City, Mo.

International Copyright Secured. 

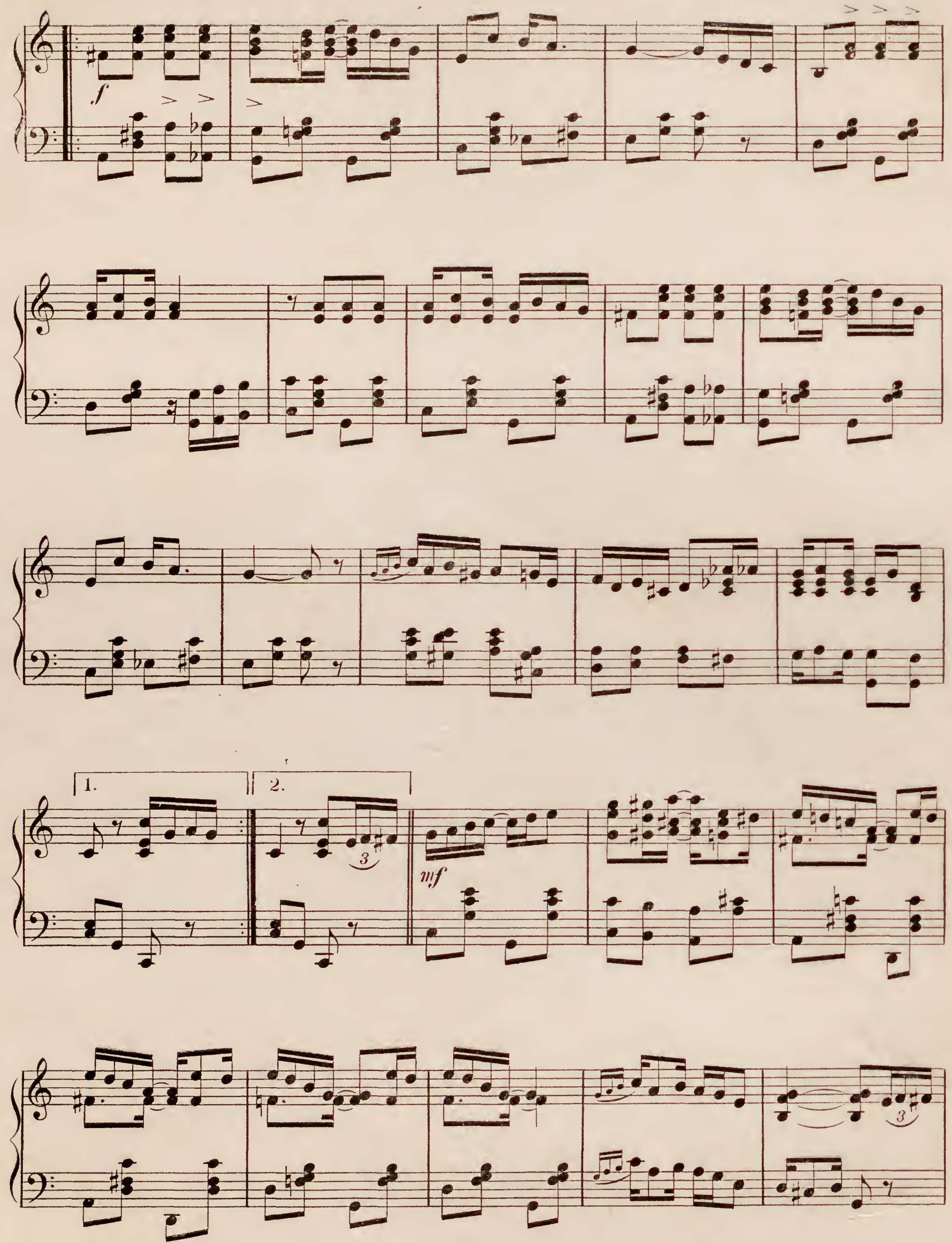

Clond Kisser -4 
4

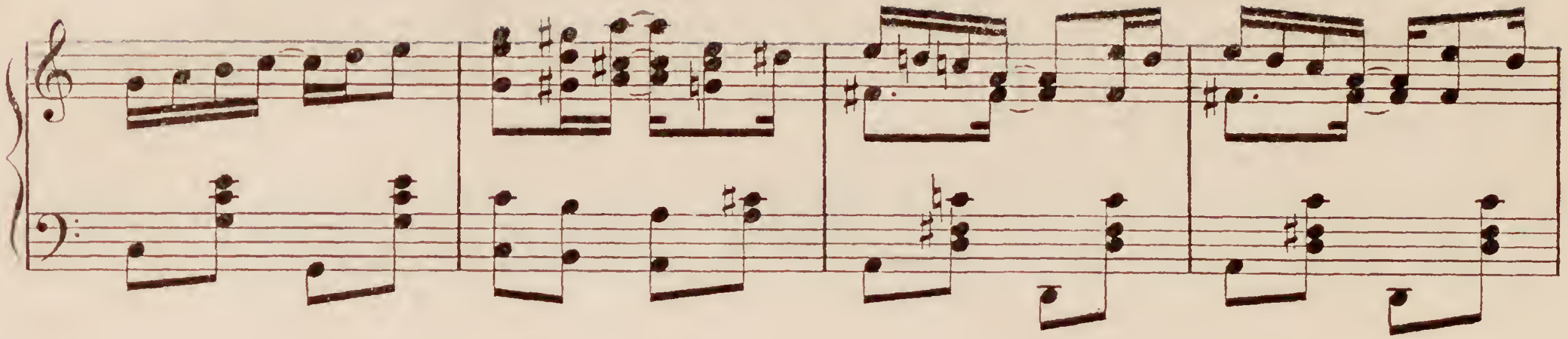

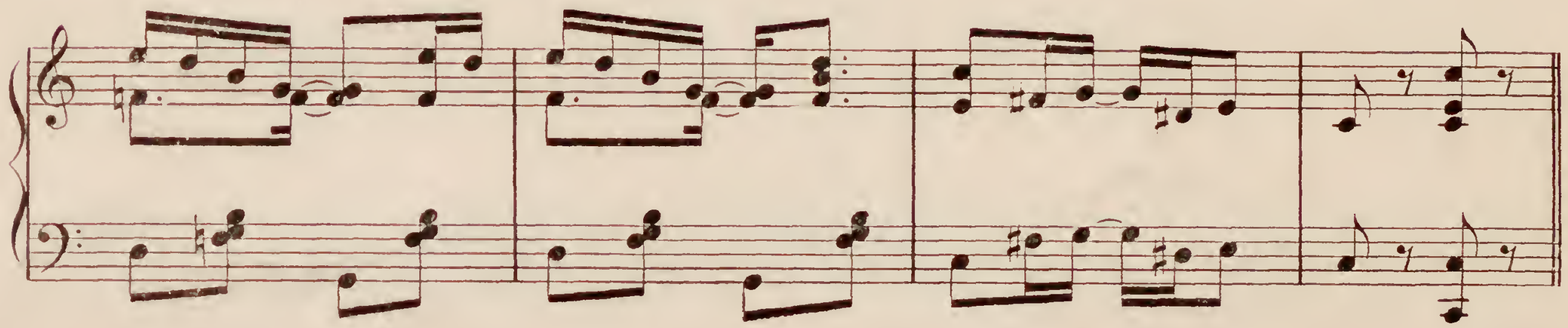

TRIO.

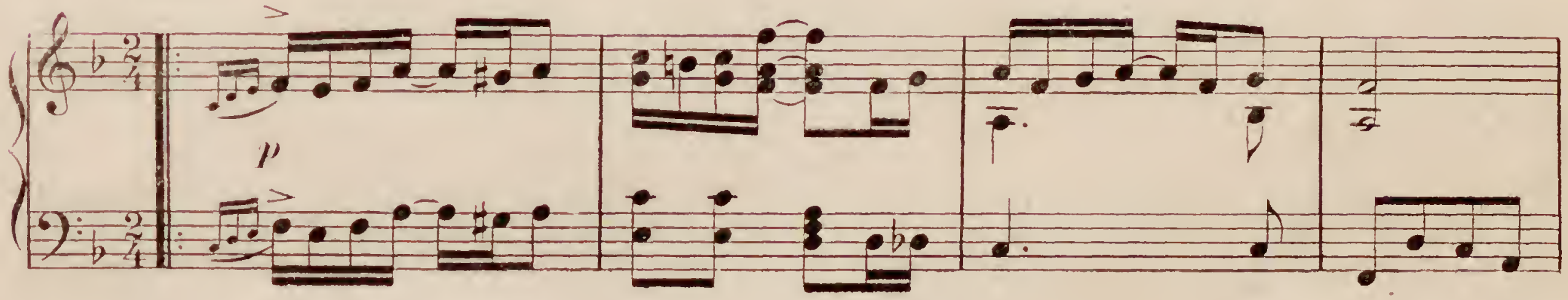

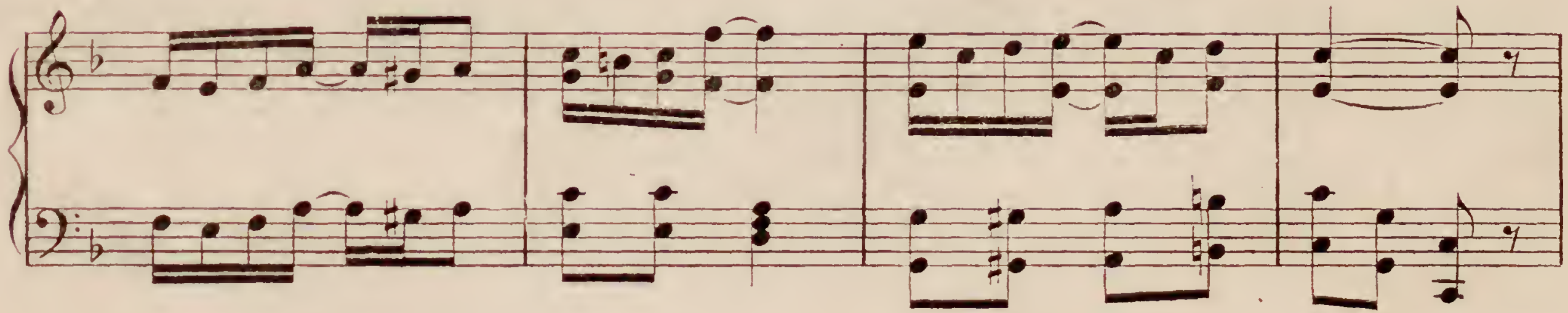

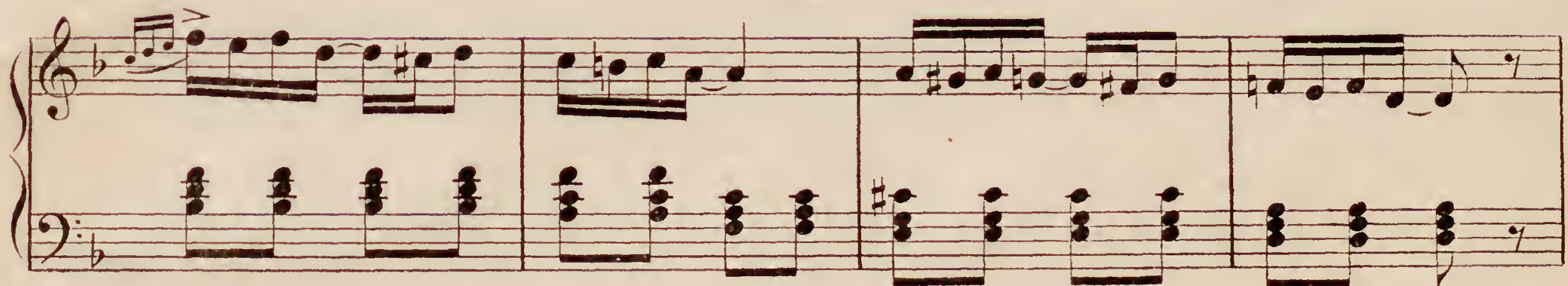

Cluud Kisses - 1 


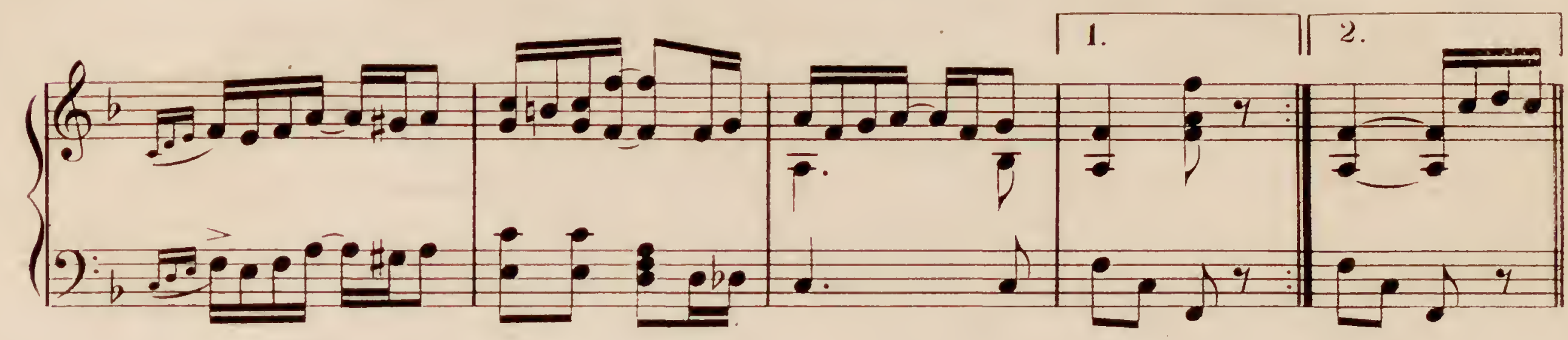
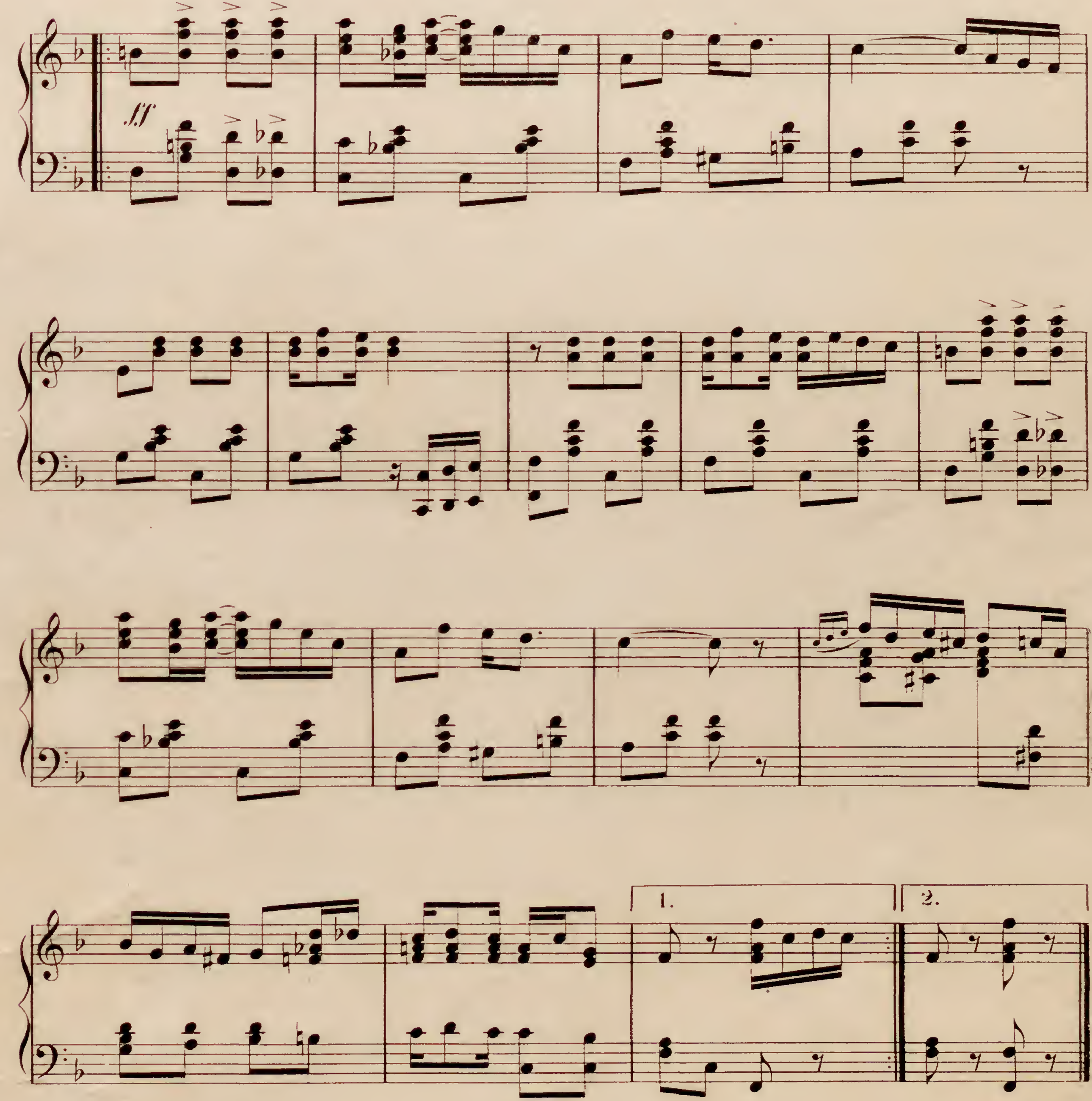

Cloud Kisser - t. 


\section{Some New Numbers, Sure to Be Popular}

By William R. Clay, Raymond Birch and Chas. L. Johnson, Writers Who Have Made Reputations for Producing Big Sellers.

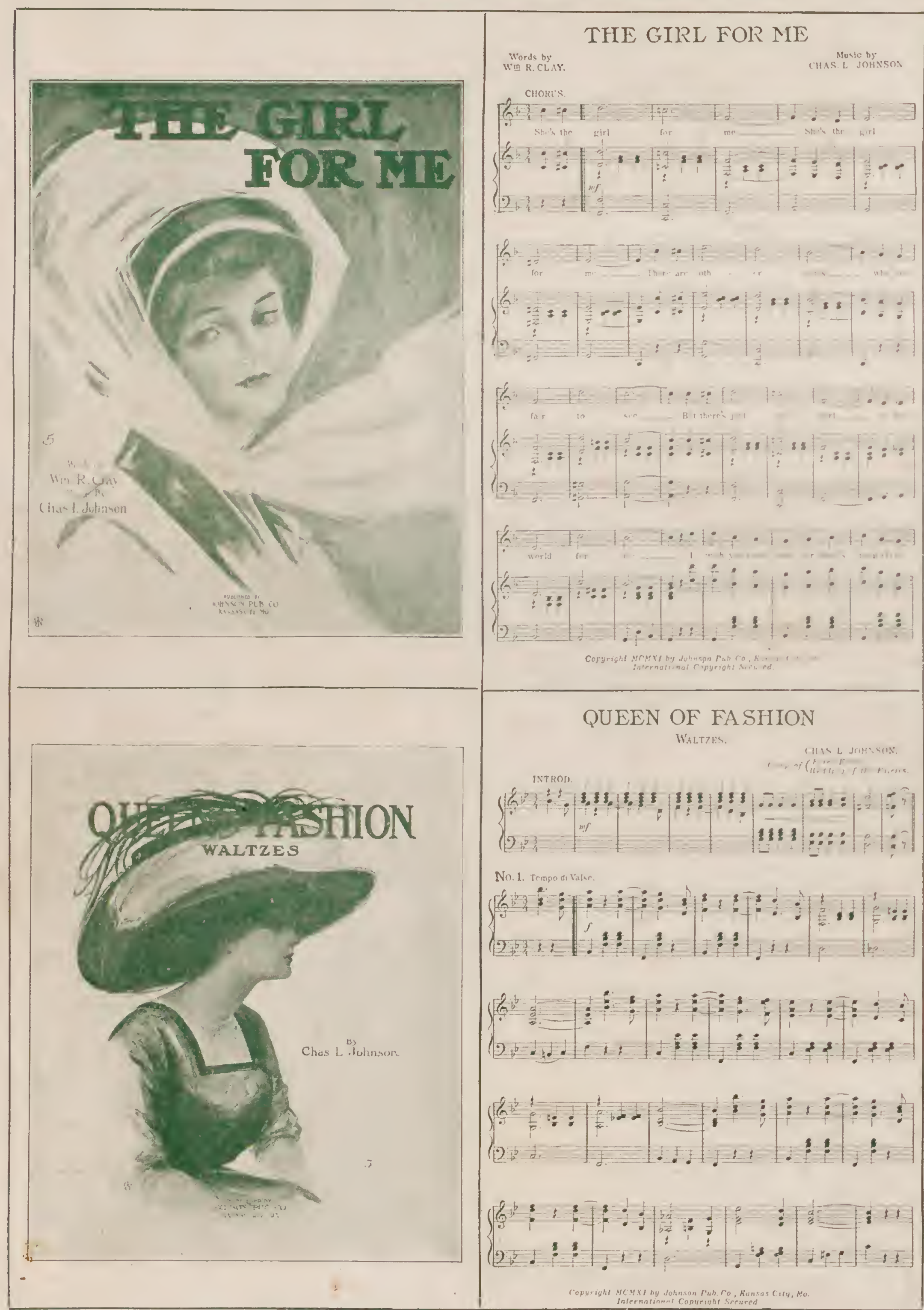

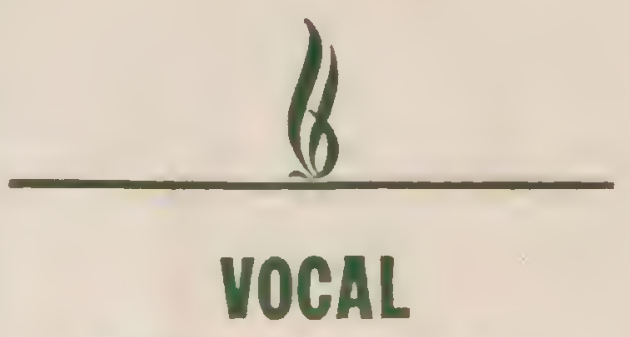

Words by William R. Clay

Music by Chas. L. Johnson

Lucy Lee

The Girl for Me

Sly Old Moon

I'll Meet You on the Golden Shore<smiles></smiles><smiles>C1=CC=C1</smiles>

\section{INSTRUMENTAL.}

Cloud Kisser

(Rag Two-Step) by Raymond Birch Queen of Fashion Waltzes (by Chas. L. Johnson)

Tar Babies Rag By Raymond Birch

\section{Melody Rag}

By Raymond Birch

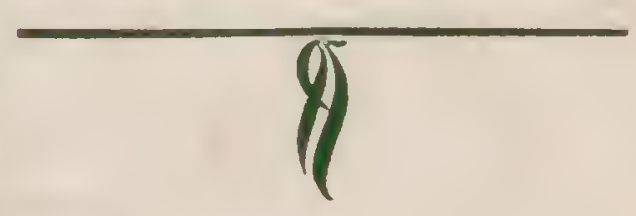

\section{JOHNSON PUBLISHING COMPANY}

For Sale at all

Music Dealers
MUSIC PUBLISHER KANSAS CITY, MO.
Sent Postpaid on Receipt of Price 